\title{
The Effect of Similarity Between a Product's Shape Properties and the Benefit Offered on Judgments and Preferences
}

\author{
Kelly Saporta-Sorozon \\ Correspondence: Kelly Saporta-Sorozon, Department of Education and Psychology, the Open University of Israel, \\ Ra'anana, Israel.
}

Received: March 8, 2019

doi:10.11114/bms.v5i2.4239

\author{
Accepted: March 26, 2019 \\ Online Published: April 28, 2019 \\ URL: https://doi.org/10.11114/bms.v5i2.4239
}

\begin{abstract}
Studies show a product's shape affects consumer judgments. Yet, the basic principle that governs shape effects is unclear. In this study, we fill this gap by demonstrating that causal-reasoning considerations govern shape effects. Specifically, people expect cause (e.g., an energy drink) and its effect (e.g., fat burning) to exhibit some degree of resemblance or congruency ("like causes like"). This expectation leads them to use the "law of similarity" heuristic when judging artifacts. In two studies, we focused on a product's shape. For half of the products, the shape was an intrinsic property of the product (i.e., had the causal power to produce the effect), and for the other half, the shape was an extrinsic property of the product. For both kinds of properties (extrinsic and intrinsic), we demonstrate that the same ad (e.g., an energy drink that "claims" to produce fat burning) is more persuasive (willingness to purchase the product, and choice between products) when the product's shape is congruent rather than incongruent (e.g., a "tall" can vs. a "short" can) with the effect promised.

We strengthen the notion that leaning on a cause-effect-similarity heuristic is very basic, by showing that choice situations accelerate the effect of congruency more for products for which the focal property is extrinsic than for products for which it is intrinsic.

In line with other studies that show causal reasoning considerations govern judgment and choice on artifacts (products), the present study demonstrates causal-reasoning considerations govern judgment and choice concerning the cause-effectsimilarity heuristic as well.
\end{abstract}

Keywords: cause-effect similarity, consumer choice, causal reasoning, extrinsic property, intrinsic property

\section{Introduction}

Imagine that while in the supermarket, you see on the beverage shelf two cans of an energy drink with the tag "Omegathe energy drink for burning fat." The two cans are identical except that one is "tall" and one is "short." Which would you prefer? Would you be indifferent? Based on people's tendency to lean on the "law of similarity" heuristic in causal reasoning (Rozin \& Nemeroff, 2002), we believe consumers will prefer the "tall" can. Specifically, people expect the cause (e.g., the height of the can) and the effect (e.g., burning fat) to exhibit some degree of physical resemblance ("like causes like"). Tall is more associated with being skinny (burning fat) than short. Thus, consumers will likely prefer the "tall" can. In the present study, we examine the influence of a cause-effect similarity in a product's shape properties on persuasion (willingness to purchase the product and choice between alternatives). We contend that because people expect a cause and its effect to be similar (Rozin \& Nemeroff, 2002), they are overly sensitive to available attributes, such as a product's shape properties, and thus tend to base their attitudes toward the product on them. Specifically, we contend that the same ad will be more persuasive when the product's shape properties are congruent with the effect promised than when they are incongruent.

\subsection{Literature Review}

\subsubsection{Impact of Cause-Effect Similarity on Judgments and Inferences}

People believe a cause and its effect should be congruent on such dimensions as size, magnitude, length, or duration (Einhorn \& Hogarth, 1986). They expect cause and effect to exhibit some degree of physical resemblance ("like causes like") and congruity in length and strength. Research indicates people rely on the cause-effect-similarity heuristic when making causal judgments. For example, Rozin, Millman, and Nemeroff (1986) demonstrate the strong impact of the cause-effect-similarity heuristic on our behavior, by using fictitious and unreasonable food appearance. Most students 
preferred a round piece of chocolate fudge to a piece with the same content but shaped to look like dog excrement. Similarly, most undergraduates were reluctant to put a fake vitamin - made of rubber - into their mouths, but they were willing to put a flat rubber sink stopper of about the same size into their mouth.

LeBoeuf and Norton (2011) demonstrate that the degree of similarity (in both size and valence) between causes and consequences affects peoples' inferences about the cause of events. For example, people inferred that an event (computer crash) was more likely the result of a large cause (widespread computer virus) if it had a large consequence (job loss) but that it was more likely the result of a smaller cause (cooling fan malfunction) if the consequence was small (the data were recovered).

Van Prooijen and Van Dijk (2014) find that events with big (vs. small) consequences increase conspiracy beliefs.

\subsubsection{Effects of Product's Shape Properties on Consumer Judgments and Preference}

Many authors agree that a product's shape packaging is an important factor that affects buying behavior (e.g., Kuvykaite, Dovaliene, \& Navickiene, 2009; Ares \& Deliza, 2010). Gupta and Kumar (2016) even assert packaging should be considered the 5th $\mathrm{P}$ of marketing. However, aproduct's packaging is a wide category and thus includes many extrinsic properties - properties that do not have the causal power to produce the effect (White, 2005) - such as the package color, texture, length, width, labels, font style, pictures, printed information, design,and so on. For example, the height of the energy-drink can described earlier is an extrinsic property.

Not only the package but also the product itself has many shape properties. We refer to these properties as intrinsic because at least some of them have the causal power to produce the effect. For example, the eyelets of a Band-Aid (aimed to heal wounds faster) is an intrinsic property because, based on previous knowledge, we know it has the causal power to produce the effect. Specifically, people believe the eyelets allow contact of the wound with the air, thereby killing bacteria and enabling a shorter healing period. Previous studies examined the effect of various aspects of a product's shape properties (extrinsic and intrinsic) on purchase decisions. Yang and Raghubir (2005) study the effect of elongated containers on perceived products' quantity. In four multi-method studies, the authors show that the more elongated a container is (bottle vs. a can of beer), the lower its perceived purchase quantity. Raghubir and Greenleaf (2006) focus on the rectangular shape of a package and find the ratio of the sides of a rectangular product (or package) influences purchase intentions and preferences. Krider, Raghubir, and Krishna (2001) focus on area comparison (Does a square pizza look larger or smaller than a circular pizza?) and propose a psychophysical model of how consumers make area-comparison judgments. Garber, Hyatt, and Boya (2009) examine the effect of a range of standard package shape types on volume perception. Results show that consumers group most existing standard packages into several distinct shape categories, such as cylinders, kegs, and bottles. Each shape type has characteristic effects on volume appearance. Geometrically complex forms appear smaller than simple forms. Becker, Thomas, Van Rompay, Schifferstein, and Galetzka (2011) examine the effect of packaging design on taste impressions. Results indicate associations depicted by shape are transferred to taste experiences. More generally, shape and color saturation may affect product evaluations and price expectations as well. Spence and Ngo (2012) review literature that focused on foods and beverages, showing that certain shapes are associated with specific tastes, flavors, and textures.

\subsection{Adopting the Causal Reasoning Framework to Study Shape Effects}

Taking together, past research has focused on trying to find the product's dimensions that affects purchase behavior, and consequently, ends up pointing to specific features that affect persuasion under specific circumstances. Because the number of shape elements that constitute a package as well as the product itself is endless, this approach is not very practical.

We propose that a more practical approach is to consider adopting an appropriate theoretical framework. Specifically, because most claims in marketing communication are causal claims (Saporta-Sorozon, 2018), we should use a causalreasoning framework in general and the cause-effect-similarity heuristic in particular to understand how shape affects a product's evaluation. The key aspect would be the degree of congruency between the cause (the product's properties) and the effect (the benefit) promised. The advantage of studying a shape's effects from the causal-reasoning perspective (cause-effect similarity) pertains to the generalization power of the findings, beyond specific features. Specifically, instead of focusing on specific features to study the effect of shapes, we can focus on the basic law - the degree of perceived congruency between a salient product property and the effect promised. Note that the same element can sometimes enhance willingness to purchase (WTP) and sometimes reduce WTP. For example, when the claim is about a drink that helps burn fat, a "tall" can is more congruent with the effect than a "short" can. The opposite could be the case if the claim is that the drink enhances resistance to stress. A "short" can, may appear more sound than a "tall" can.

Saporta-Sorozon (2018) demonstrates that congruency between the specific extrinsic properties — packaging color —and the benefit promised affect WTP and preference. In this study, we strengthen the same notion by demonstrating it for several dimensions of intrinsic as well as extrinsic shape properties, such as texture, height, depth, and so on. 


\subsection{Grasping Cause-Effect Congruency for Extrinsic vs. Intrinsic Product Properties.}

Studies show two systems of thinking determine consumers' decisions: System 1 is experiential, affective, and intuitive and thus involves minimal effort and deliberation; System 2 is rational, deliberative, and analytical and thus involves some effort (Kahneman, 2011; Stanovich \& West, 2000). Rozin and Nemeroff (2002) contend that using the cause-effectsimilarity heuristic is straightforward, primitive, and, in a way, automatic, and thus invites System 1 to operate.

The congruency (or in congruency) of an extrinsic product property and the effect promised is straightforward because it is based on superficial match considerations. We easily see that a smooth texture of a patch (aimed to prevent mosquito bites) is congruent with the effect promised (intact skin), whereas a lumpy texture of the same patch is not.

Yet, grasping the congruency (or in congruency) of an intrinsic property, is not so immediate and requires some effort. Generally, we exert such effort by searching for the appropriate mechanism that explain how the cause (product property) produces the effect (benefit). For example, we see a Band-Aid (aimed to heal wounds faster) with eyelets as more congruent with the effect promised (faster healing) than an identical Band-Aid but with drawn eyelets. The reason is that, based on previous knowledge, we recruit the appropriate mechanism by which the eyelets produce the effect-allowing contact of the wound with the air, thereby killing bacteria and enabling a shorter healing period.

Although recruiting the appropriate mechanism involves some effort, people do it automatically. Many studies show that mechanistic explanations play a central role in our causal reasoning. People appear to depend on explanation in many ways, such as to make sense of causal claims (Kuhn, 2001), to explain events' occurrence (Ahn, Kalish, Medin, \& Gelman, 1995), to justify or argue for a claim (Glassner, Weinstocks, \& Neuman, 2005; Kuhn, 2001), and to increase their willingness to pay for products (Fernbach, Sloman, Louis, \& Shube, 2013; Saporta-Sorozon, 2018). Thus, we believe that also for intrinsic properties congruency between them and the benefit promised affect persuasion. Specifically, we hypothesize the following:

Hypothesis 1. Consumers are more persuaded (willing to choose the product and to purchase it) when the package's orproduct's shape property is associated and thus congruent with the benefit promised than when it is incongruent (associated with the opposite).

\section{Pilot Study}

To choose appropriate materials for the two experiments, we conducted a pilot study. Inspired by real products, we created six products: three in which the focal property was extrinsic and three in which the focal property was intrinsic. For example, to represent an intrinsic property, we presented a picture of a bubble wrap (thicker) versus a foam wrap (thinner) designed to protect objects. To represent an extrinsic property, we presented, for example, a picture of a "tall" versus "short" can containing an energy drink intended to help burn fat. (For all materials, see Appendix A).

\subsection{Method}

Thirty-six individuals participated in the pilot study designed to ensure the focal-shape properties were congruent or incongruent with the benefit offered. We exposed participants to six benefit terms (e.g., skinny) and six terms that represent the "problem" (e.g., fat). We asked participants to choose which of two shapes was more associated with the benefit/problems.

\subsection{Results}

Table 1 presents for each product the percentage of participants who chose the congruent and incongruent shape as being associated with the word that expressed the benefit and the word that expressed the opposite (problem). 
Table 1. Percentage of participants who chose the congruent and the incongruent-shape word as being associated with the term that represented the benefit and the term that represented the problem, for each product

\begin{tabular}{|c|c|c|c|}
\hline Product & $\begin{array}{l}\text { Benefit/ } \\
\text { opposite }\end{array}$ & $\begin{array}{l}\text { Shape } \\
\text { property }\end{array}$ & $\begin{array}{l}\text { Percent choosing the shape } \\
\text { property as associated with } \\
\text { the benefit/opposite }\end{array}$ \\
\hline \multirow[t]{4}{*}{ 1. An energy drink for burning fat } & \multirow[t]{2}{*}{ fat } & tall & $21.9 \%$ \\
\hline & & Short & $78.1 \%$ \\
\hline & \multirow[t]{2}{*}{ skinny } & tall & $81.0 \%$ \\
\hline & & short & $19.1 \%$ \\
\hline \multirow[t]{4}{*}{ 2. A dish soap for shining dishes } & \multirow[t]{2}{*}{ dull } & Opaque & $85.7 \%$ \\
\hline & & transparent & $14.3 \%$ \\
\hline & \multirow[t]{2}{*}{ Shiny } & Opaque & $13.3 \%$ \\
\hline & & transparent & $86.7 \%$ \\
\hline \multirow[t]{4}{*}{ 3. A patch that wards off mosquitoes } & \multirow[t]{2}{*}{ Sting } & smooth & $6.7 \%$ \\
\hline & & lumpy & $93.3 \%$ \\
\hline & \multirow[t]{2}{*}{ Calm } & smooth & $96.2 \%$ \\
\hline & & lumpy & $3.8 \%$ \\
\hline \multirow[t]{4}{*}{ 4. A patch that helps wounds heal faster } & \multirow[t]{2}{*}{ wound } & Sealed & $61.9 \%$ \\
\hline & & ventilated & $38.1 \%$ \\
\hline & \multirow[t]{2}{*}{ cure } & Sealed & $19,0 \%$ \\
\hline & & ventilated & $81.0 \%$ \\
\hline \multirow{4}{*}{$\begin{array}{l}\text { 5. An ecological ball that protects clothes } \\
\text { from wrinkling in the dryer }\end{array}$} & \multirow{2}{*}{ crumple } & Uneven texture & $80.0 \%$ \\
\hline & & spiny texture & $20.0 \%$ \\
\hline & \multirow[t]{2}{*}{ smooth } & Uneven texture & $46.7 \%$ \\
\hline & & spiny texture & $53.3 \%$ \\
\hline \multirow{4}{*}{$\begin{array}{l}\text { 6. Packaging that protects objects from } \\
\text { damages such as breaking }\end{array}$} & \multirow{2}{*}{ damage } & thin & $78.1 \%$ \\
\hline & & thick & $21.9 \%$ \\
\hline & \multirow[t]{2}{*}{ protect } & thin & $29.5 \%$ \\
\hline & & thick & $70.5 \%$ \\
\hline
\end{tabular}

Table 1 demonstrates that, as expected, for the term that expresses the benefit, the percent of participants who chose the congruent-shape property (as being associated with the property) was much higher than the percentage of participants who chose the incongruent-shape property, and vice versa.

\section{Study 1}

\subsection{Method}

\subsubsection{Participants and Design}

Sixty-two undergraduate students (males $=50.7 \%, M_{\text {age }}=36.97 ; S D_{\text {age }}=13.31$ ) participated for credit in a web-based study using two conditions of cause-effect congruency in shape (congruent and incongruent) and kind of attribute (extrinsic and intrinsic) in a within-subjects design. We presented participants with the same six products as in the pilot study. We randomly assigned participants to the combination of a specific product and the congruency condition by kind of attribute.

\subsubsection{Materials, Measures, and Procedure}

Each participant saw the picture of each of the six products: For three, the product's shape property was congruent with the benefit promised, and for the other three, the product's shape was incongruent with the benefit promised (see Appendix A for materials). Importantly, each picture included the product in one of the conditions. After participants watched each 
picture, we measured the following:

a. Willingness to purchase. Participants were asked to indicate the probability that they would purchase the product if they needed one that provided the benefit offered, on a scale ranging from 1 (definitely not) to 6 (definitely yes).

b. Sense of the delivery of the benefit. Participants were asked to indicate the extent to which the product in the picture gave them the feeling that it would deliver the benefit, on a scale ranging from 1 (not at all) to 6 (largely gives).

\subsection{Results}

\subsubsection{Willingness to Purchase}

Table 2 presents the results for the 2 (cause-effect congruency: incongruent, congruent) by 2 (kind of attribute: extrinsic, intrinsic) analysis of variance.

Table 2. Results for the 2 (cause-effect congruency: incongruent, congruent) by 2 (kind of cause-attribute: extrinsic, intrinsic) mixed ANOVA for willingness to purchase the product

\begin{tabular}{lll}
\hline Effect & $\mathrm{F}(1,63)$ & $\eta_{\mathrm{p}}^{2}$ \\
\hline Congruency & $4.43^{*}$ & .07 \\
\hline kind of cause-attribute & $15.82^{* * *}$ & .19 \\
\hline congruency * kind of cause-attribute & $<1$ & - \\
\hline
\end{tabular}

$* \mathrm{p}<.05 * * * \mathrm{p}<.001$

As table 2 shows, congruency affected WTP (Hypothesis 1). As hypothesized, willingness to purchase the product was higher when the cause and its effect were congruent than when they were incongruent $\left(M_{\text {cong }}=3.83, S E=0.14 \mathrm{vs.} M_{\text {incong }}=\right.$ $3.52, S E=0.15$ ). In addition, the effect of the kind of cause-attribute was also significant. As expected, WTP for the product whose shape property represented an intrinsic attribute (which spontaneously elicits the appropriate mechanism) was higher than for the product whose shape property $\operatorname{did} \operatorname{not}\left(M_{\text {intrinsic }}=3.93, S E=0.14\right.$ vs. $\left.M_{\text {extrinsic }}=3.42, S E=0.14\right)$. The two-way interaction was not significant.

\subsubsection{Sense of Benefit Delivery}

Table 3 presents the results for the 2 (cause-effect congruency: incongruent, congruent) by 2 (kind of cause-attribute: extrinsic, intrinsic) mixed analysis of variance for sense of benefit delivery.

Table 3. Results for the 2 (cause-effect congruency: incongruent, congruent) by 2 (kind of cause-attribute: extrinsic, intrinsic) mixed ANOVA for sense that the product would deliver the benefit

\begin{tabular}{lll}
\hline Effect & $\mathrm{F}(1,63)$ & $\eta^{2}$ \\
\hline Congruency & $13.60^{* * *}$ & .18 \\
\hline kind of cause-attribute & $24.49^{* * *}$ & .29 \\
\hline congruency $*$ kind of cause-attribute & 1.65 & - \\
\hline${ }^{p}<.05 * * * \mathrm{p}<.001$ & &
\end{tabular}

As Table 3 shows, the picture is similar for WTP and more pronounced. As expected, the sense of benefit delivery was higher when cause and effect were congruent than when they were incongruent $\left(M_{\text {cong }}=3.36, S E=0.14\right.$ vs. $M_{\text {incong }}=2.77$, $S E=0.14)$. In addition, the effect of the kind of cause-attribute was also significant. As expected, the sense of benefit delivery for products whose shape represented an intrinsic attribute was higher than for products whose shape represented an extrinsic attribute $\left(M_{\text {intrinsic }}=3.46, S E=0.14\right.$ vs. $\left.M_{\text {extrinsic }}=2.68, S E=0.13\right)$. The two-way interaction was not significant.

\subsection{Discussion}

The results of Study 1 demonstrate that, indeed, the principle of cause-effect similarity governs consumers' judgment of products. Specifically, as predicted (Hypothesis 1), consumers are more willing to purchase a product when the product's shape property is associated and thus congruent with the benefit promised than when it is incongruent (associated with the opposite). As for the kind of attribute, products whose shape properties were intrinsic (thus spontaneously eliciting the appropriate mechanism) were more persuasive than products whose shape properties were extrinsic. These results are in line with a large body of studies showing the dominance of the spontaneous tendency to search for a mechanism that will explain how the cause produces the effect (Ahn et al., 1995; Lombrozo, 2006). 


\section{Study 2}

In Study 1, we measured persuasion by asking participants to rate their willingness to purchase the product, via separateevaluation platform. We exposed each participant to both conditions (congruent and incongruent) but for different products and on different slides. Following several authors demonstrating that a joint-evaluation platform investigates different premises (Hsee, 1996; Tversky and Kahneman, 1983), and thus can reveal other aspects of the same topic, we designed study 2. In study 2, we exposed each participant to both conditions (congruent and incongruent) for the same products and on the same slide. On each slide, participants saw the same product in its two conditions - side by sideand had to choose between them.

As demonstrated in study 1, the degree of congruency between the benefit promised and product property affect WTP for both kinds of properties - extrinsic and intrinsic. Yet, we contend that this impact is larger for extrinsic than intrinsic properties, because, as discussed earlier, grasping congruency for intrinsic properties requires some effort. However, the difference in effect size between extrinsic and intrinsic properties cannot be manifested in separate evaluations, for two reasons. First, although grasping congruency for intrinsic properties requires some effort, this effort is still very small, because people automatically recruit the appropriate mechanisms to explain how the intrinsic product property produces the effect. Furthermore, to reveal the small difference, we need circumstances that permit comparison between the options. In study 1, participants did not directly compare the options: They not only saw different products, but also saw only one product on each slide. In the joint-evaluation platform used in study 2, we forced participants to compare the options, thus permitting the difference in the effect size between extrinsic and intrinsic properties to manifest.

We predict the following:

Hypothesis 2. For contexts that enable direct comparison between congruent and incongruent options (i.e., joint evaluation), the effect of cause-effect congruency (between a product's shape and the benefit promised) on persuasion is more pronounced for extrinsic than intrinsic properties.

\subsection{Method}

\subsubsection{Participants and Design}

One hundred twenty-five undergraduate students (males $=50.8 \%, M_{\mathrm{age}}=40.77 ; S D_{\mathrm{age}}=15.97$ ) participated for credit in a web-based study. We used a mixed-subjects design of 6 (products - a within-subjects factor) by 2 (kind of attribute: extrinsic, intrinsic) by 2 (the location of the product: each of the four combinations of congruency and kind of attribute presented on the right of the slide or on the left—as a between-subject factor). Participants saw all six products, whereas we randomly assigned participants to one of the locations.

\subsubsection{Materials, Measures, and Procedure}

Each participant saw six slides, one for each product (see Study 1), with the two pictures of the product appearing side by side in each slide. After participants saw each slide, we measured the following:

a. Preference/Choice. We asked participants which of the two products in the slide they would prefer if they needed such product: (a) the product on the left (could be congruent or incongruent, with an extrinsic or intrinsic attribute), (b) the product on the right (could be congruent or incongruent, with an extrinsic or intrinsic attribute depending on (a)), or(c) indifferent.

b. Sense of the benefit delivery (similar to Study 1). Participants were asked to indicate the extent to which each of the two pictures of the product in the slide gave them the feeling it would deliver the benefit, on a scale ranging from 1 ( $n$ ot at all) to 6 (largely gives).

\subsection{Results}

\subsubsection{Preference}

For each participant, we produced four indexes: two for the three products with the extrinsic properties and two for the three products with the intrinsic properties. Specifically, we counted the times (out of three) the participant chose the pictures for the congruent and extrinsic attribute, congruent and intrinsic attribute, incongruent and extrinsic attribute, and incongruent and intrinsic attribute. Note these numbers do not necessarily sum to three, because for each product, the participant could choose the third possibility, namely, "indifferent."

Table 4 presents the results of the 2 (cause-effect congruency: incongruent, congruent) by 2 (kind of attribute: extrinsic, intrinsic) analysis of variance. 
Table 4. Results for the 2 (cause-effect congruency: incongruent, congruent) by 2 (kind of cause-attribute: extrinsic, intrinsic) mixed analysis of variance for preference.

\begin{tabular}{llc}
\hline Effect & $\mathrm{F}(1,125)$ & $\eta_{\mathrm{p}}^{2}$ \\
\hline Congruency & $203.70^{* * *}$ & .62 \\
\hline kind of cause-attribute & $27.06^{* * *}$ & .18 \\
\hline congruency * kind of cause-attribute & $15.02 * * *$ & .11 \\
\hline
\end{tabular}

$* * * \mathrm{p}<.001$

As Table 4 shows, congruency strongly affected choice (Hypothesis 1).As expected, the number of products chosen was higher when cause and effect were congruent than when they were incongruent $\left(M_{\text {congruent }}=1.55, S E=0.06\right.$ vs. $M_{\text {incongruent }}=$ $0.36, S E=0.04)$. The effect of the kind of cause-attribute was also significant. However, the means were in the opposite direction relative to study 1 ; the number of products chosen was higher when the shape represented an extrinsic property than when it represented an intrinsic attribute $\left(M_{\text {extrinsic }}=1.08, S E=0.04\right.$ vs. $\left.M_{\text {intrinsic }}=0.83, S E=0.03\right)$. As predicted, the two-way interaction was significant.

As Figure 1 shows, indeed, when participants saw the two products side by side, the effect of congruency was more pronounced for extrinsic attributes than for intrinsic attributes.

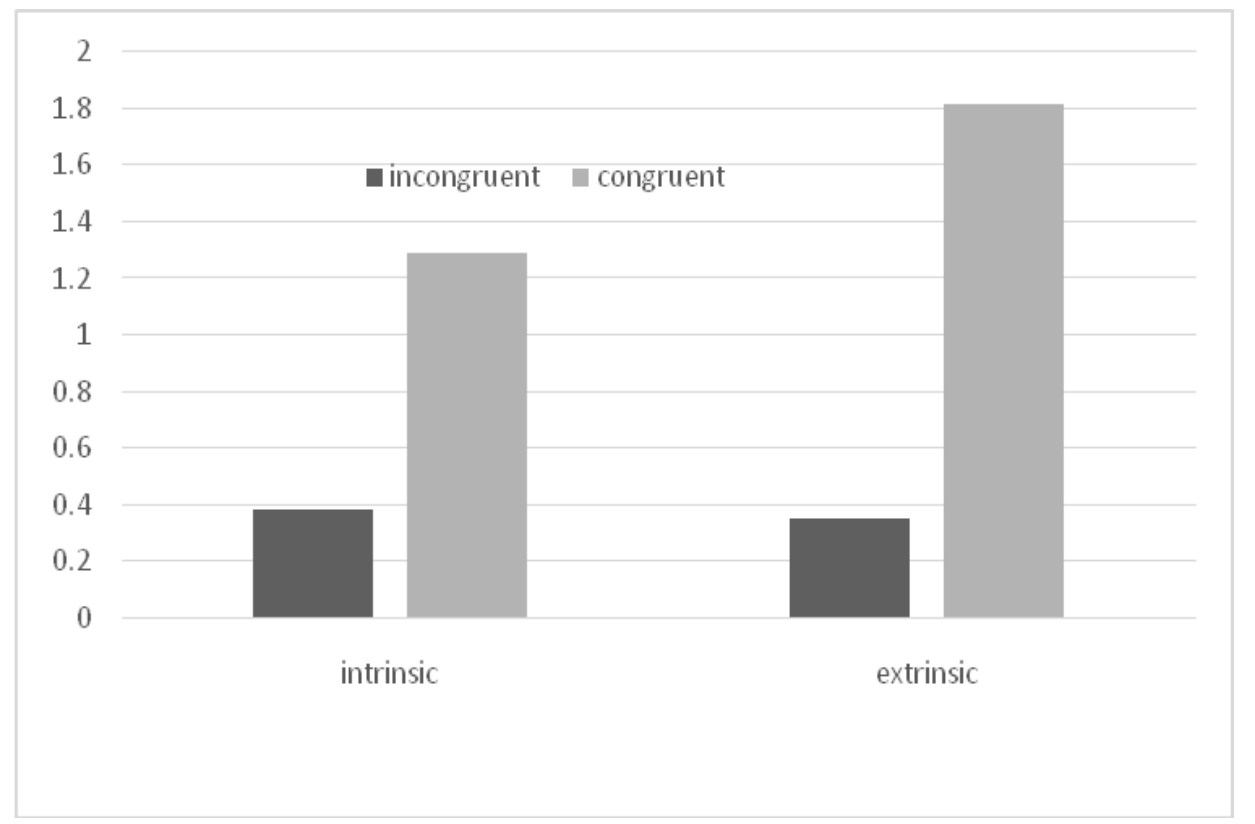

Figure 1. Means of choice as a function of cause-effect congruency (incongruent vs. congruent) and the kind of causeattribute (extrinsic vs. intrinsic)

\subsubsection{Sense of Benefit Delivery}

Table 5 presents the results for the 2 (cause-effect congruency: incongruent, congruent) by 2 (kind of cause-attribute: extrinsic, intrinsic) analysis of variance for sense of benefit delivery.

Table 5. Results for the 2 (cause-effect congruency: incongruent, congruent) by 2 (kind of cause-attribute: extrinsic, intrinsic) analysis of variance for sense that the product would deliver the benefit

\begin{tabular}{lll}
\hline Effect & $\mathrm{F}(1,124)$ & $\eta_{\mathrm{p}}^{2}$ \\
\hline congruency & $318.26^{* * *}$ & .72 \\
\hline kind of cause-attribute & $31.15^{* * *}$ & .20 \\
\hline congruency * kind of cause-attribute & $22.85 * * *$ & .16 \\
\hline
\end{tabular}

$$
* * * \mathrm{p}<.001
$$

As Table 5 shows, the two main effects and the interaction were significant. As predicted, sense of benefit delivery was higher when cause and effect were congruent than when they were incongruent $\left(M_{\text {cong }}=4.39, S E=0.08\right.$ vs. $M_{\text {incong }}=2.96$, $S E=0.08)$. The sense of benefit delivery for products whose shape represented an intrinsic property was higher than for 
products whose shape represented an extrinsic property $\left(M_{\text {intrinsic }}=3.84, S E=0.08\right.$ vs. $\left.M_{\text {extrinsic }}=3.51, S D=0.08\right)$. In addition, the two-way interaction: cause-effect congruency by kind of cause-attribute was significant.

As Figure 2 shows, the mode of the interaction is similar to that obtained for choice. The effect of congruency on sense of benefit delivery was larger for extrinsic properties.

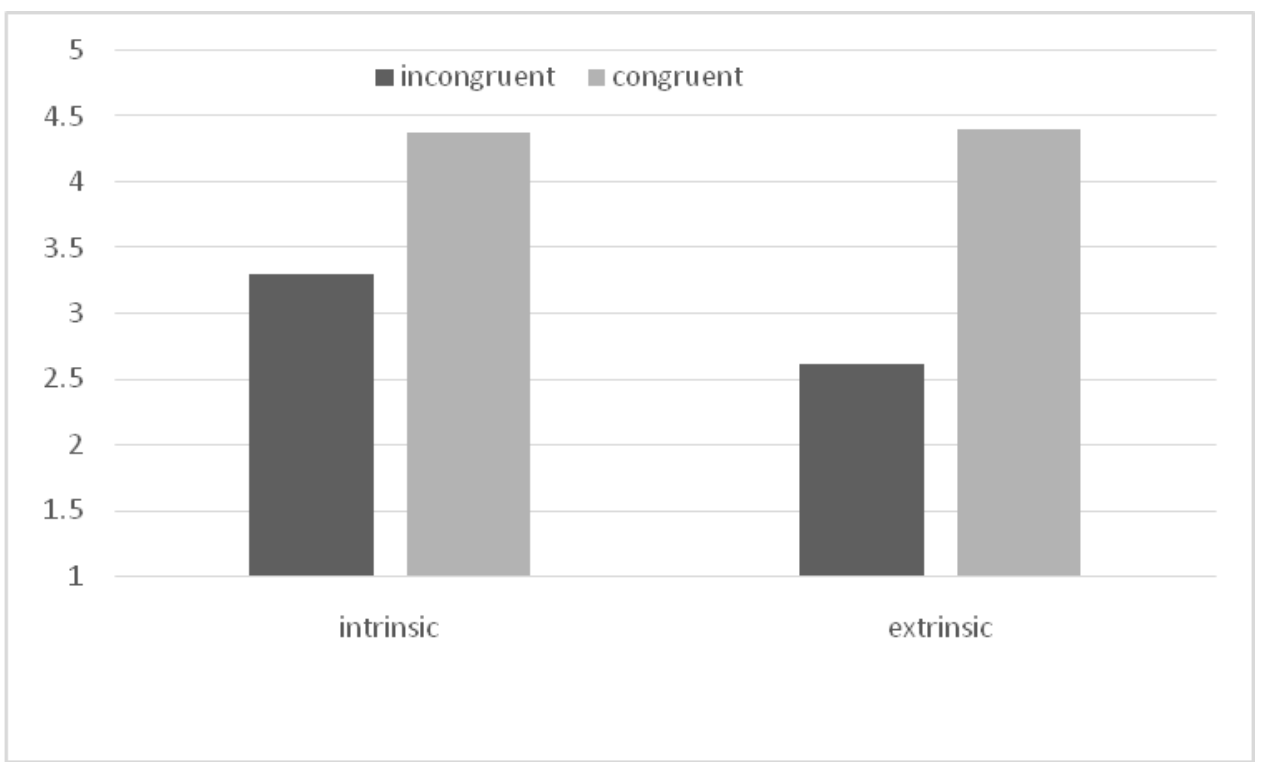

Figure 2. Means sense of benefit delivery as a function of cause-effect congruency (incongruent vs. congruent) and the kind of cause attribute (extrinsic vs. intrinsic)

\subsection{Discussion}

The results of study 2 replicate the results of study 1 for another measure of persuasion - choice between alternatives. As predicted (Hypothesis 1), participants more often chose the alternative whose causal-shape-property - whether extrinsic or intrinsic - was congruent with the benefit promised than when it was incongruent. Moreover, the joint-evaluation platform we use in study 2 reveals the difference in the size effect of congruency for the two product properties -intrinsic and extrinsic. However, the main effect of congruency is much stronger, attesting to the robustness of the impact of congruency on choice.

\section{General Discussion}

The present study focused on consumers' tendency to lean on the cause-effect-similarity heuristic (Rozin \& Nemeroff, 2002) when judging artifacts (products) and choosing between alternatives. Specifically, we examined the influence of congruency between extrinsic and intrinsic product properties (cause) and the benefit (effect) promised on persuasion (WTP and choice). We expected that because leaning on the cause-effect-similarity heuristic is a basic tendency that invites System 1 to operate (Rozin \&Nemeroff, 2002),participants would prefer alternatives and would be more willing to purchase them when a salient shape property (intrinsic or extrinsic) was congruent with the benefit promised than when it was incongruent.

To check our hypotheses, we first designed six products (similar to real-life products), each intended to deliver a certain benefit: For three of the products, the focal property was extrinsic, and for the other three, it was intrinsic. Then, we designed two versions of each product: one for which the focal property was congruent with the intended cause, and one for which it was not. We conducted two studies, using different evaluation platforms. In Study 1, we used a separateevaluation platform - on each slide, participants saw only one product, and then rated their WTP for the product. We exposed participants to the two conditions (congruent and incongruent) but for different products on different slides; thus, we did not permit any direct comparison between congruency conditions. In Study 2, we used a joint-evaluation platform - we presented the two versions of the product (congruent and incongruent) side by side on the same slide, and participants chose between them, thus "forcing" them to compare the options.

We demonstrated that the same ad (e.g., a patch intended to prevent mosquito bites) was more persuasive (WTP and choice) when its shape (e.g., its texture) was congruent (smooth) with the effect promised (intact skin) than when it was not congruent/opposite (lumpy skin). We obtained the same results for intrinsic product properties. The same ad (e.g., a Band Aid intended to heal wounds faster) was more persuasive (WTP and choice) when its shape (e.g., its texture) was congruent (includes eyelet, which permit air contact with the wound, thereby killing bacteria) with the effect promised 
(faster healing) than when it was not congruent/opposite (drawn eyelets).

\subsection{Theoretical Implications}

The findings of the present study strengthen the notion emphasized by Rozin and Nemeroff (2002) that using the causeeffect-similarity heuristic is straightforward, primitive, and, in a way, automatic, which "recruits" System 1- "the intuitive-thinking system"- to operate (Kahneman, 2003). In the study on the same general topic, Saporta-Sorozon (2018) support this assertion by focusing on a specific extrinsic attribute of the product - its color. The results of the present study strengthen this notion by focusing on other shape properties of the product: intrinsic and extrinsic. Consumers seem to lean heavily on the fast and frugal cause-effect-similarity heuristic when judging artifacts and choosing between them.

Studying the effect of a product's properties on judging artifacts, from the causal-reasoning perspective in general and cause-effect similarity in particular, permits generalization of the findings, beyond specific features. Specifically, instead of focusing on specific features to study the effects of a product's properties, we can focus on the basic law-degree of perceived congruency between a salient product property and the effect promised.

The results of the present study join with other studies that focus on the effects of causal-reasoning principles on judgments and inferences concerning artifacts (products) (e.g., Saporta-Sorozon, Danziger, \& Sloman, 2017; SaportaSorozon \& Bar-Eli, 2017; Saporta-Sorozon, 2018). Thus, it encourages studying the artifacts' (products') effects using the causal-reasoning framework.

\subsection{Limitations}

In the present study, we used a variety of products, some designed to affect the human body (internally — an energy drink intended to helps burn fat; or externally — a patch intended to ward off mosquitoes, a Band-Aid aimed to heal wounds faster) and others designed to affect objects (a dish soap, an ecological ball designed to prevent laundry from crumpling, a wrap aimed to protect objects). We expect a similar pattern of results for any type of product. Yet, the effect of congruency needs to be checked in variety of product properties for other types of products, such as cars, spas, drugs, food supplements (e.g. vitamins, calcium, magnesium etc.), hygienic products (e.g., toothpaste, skin protectors), cosmetics, detergents, and high-tech products.

Another way to check the robustness of the cause-effect-similarly heuristic is to compare the effect of congruency with respect to different platforms and methods of advertising, such as printed advertising, outdoor advertising, mobile advertising, digital advertising, and so on. Again, we expect the same results for different methods of advertising. Our findings show the effect of cause-effect congruency is much stronger when the platform permits a direct comparison between the options. Thus, we expect a greater impact of congruency when the advertising platform permits joint evaluation.

\subsection{Practical Implications and Conclusions}

This study makes several important contributions to the field of consumer behavior. First, we point to the underlying mechanism responsible for the effect of product properties on persuasion. Thus, we provide a strong tool that managers can use when designing their products. The present study, as well as Saporta-Sorozon (2018), demonstrates consumers may be sensitive and thus affected by irrelevant product properties. This fact may encourage managers to be careful when designing a product. Also in this study, we used two kinds of evaluation, separate and joint, both of which simulate different contexts: Separate evaluation simulates a context in which the options are scattered on the shelves (real or virtual), and joint evaluation simulates a context in which the options appear side by side on the shelves. Thus, the fact that the size of the cause-effect-similarity effect was much larger when consumers could directly compare the alternatives can be of a big practical importance.

Finally, the findings of the present study are in line with other studies showing causal-reasoning considerations govern judgment and choice on artifacts (e.g., Fernbach et al., 2013; Saporta-Sorozon, 2018), thus encouraging the consideration of the causal-reasoning platform to study consumer judgments and decision-making. The causal-reasoning platform's ability to study what affects consumers' judgments and decision-making is not surprising given that causal claims are very common in marketing communication (Saporta-Sorozon \& Bar-Eli, 2018). 


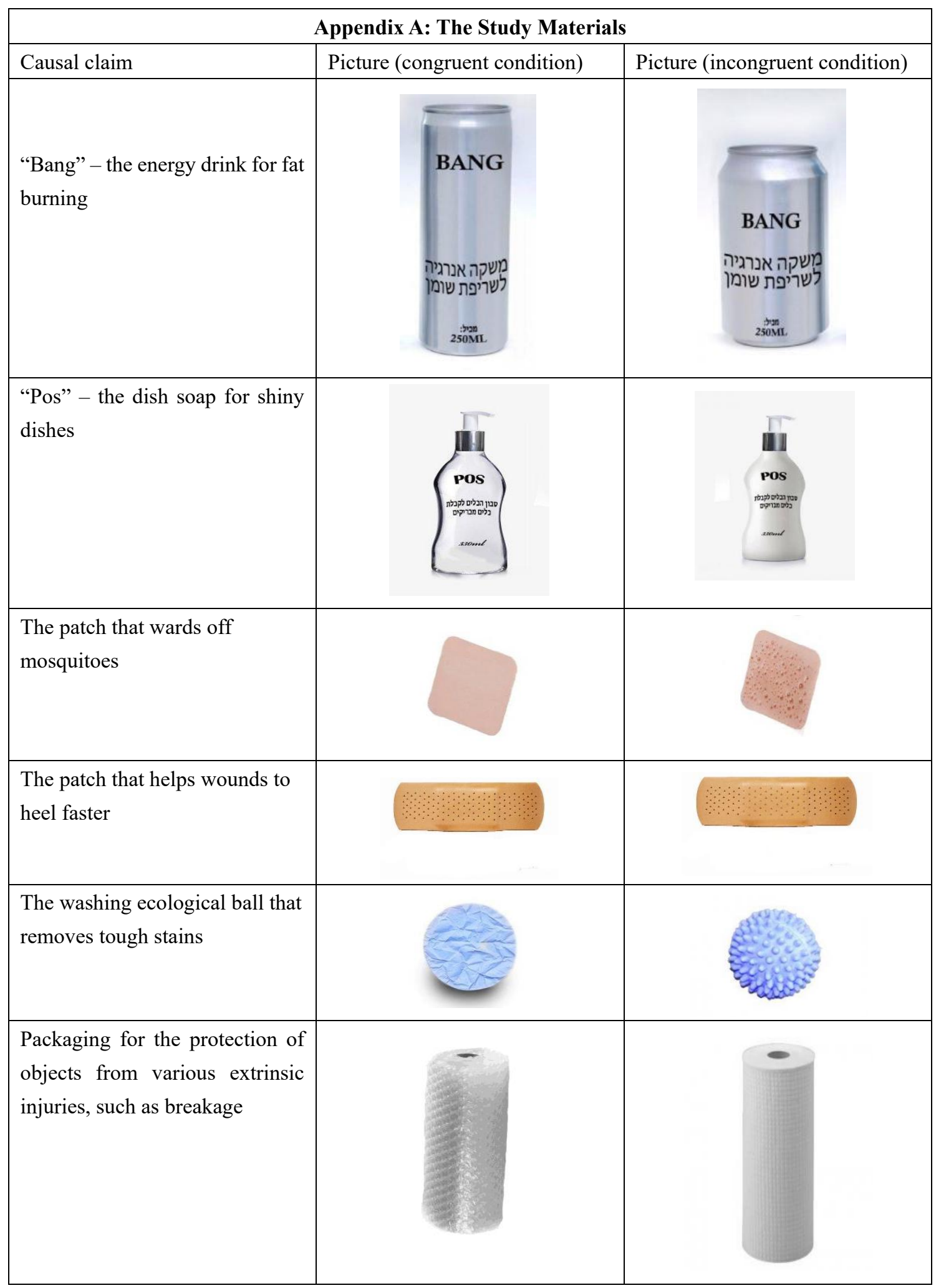




\section{References}

Ahn, W., Kalish, C. W., Medin, D. L., \& Gelman, S. A. (1995). The role of covariation versus mechanism information in causal attribution. Cognition, 54, 299-352. https://doi.org/10.1016/0010-0277(94)00640-7

Ares, G., \& Deliza, R. (2010). Studying the Influence of Package Shape and Color on Consumer Expectations of Milk Desserts Using Word Association and Conjoint Analysis. Food Quality and Preference, $21,930-937$. https://doi.org/10.1016/j.foodqual.2010.03.006

Becker, L., van Rompay, T. J., Schifferstein, H. N., \& Galetzka, M. (2011). Tough package, strong taste: The influence of packaging design on taste impressions and product evaluations. Food Quality and Preference, 22(1), 17-23. https://doi.org/10.1016/j.foodqual.2010.06.007

Einhorn, H. J., \& Hogarth, R. M. (1986). Judging probable cause. Psychological Bulletin, 99, 3-19. https://doi.org/10.1037/0033-2909.99.1.3

Fernbach, P. M., Sloman, S. A., Louis, R. S., \& Shube, J. N. (2013). Explanation fiends and foes: How Mechanistic detail determines understanding and preference. Journal of Consumer Research, 39(5), 1115-1131. https://doi.org/10.1086/667782

Garber, L. L., Hyatt, E. M., \& Boya, Ü. Ö. (2009). The effect of package shape on apparent volume: an exploratory study with implications for package design. Journal of marketing theory and practice, 17(3), 215-234. https://doi.org/10.2753/MTP1069-6679170302

Glassner, A., Weinstock, M., \& Neuman, Y. (2005). Pupils' evaluation and generation of evidence and explanation in argumentation. British Journal of Educational Psychology, 75(1), 105-118. https://doi.org/10.1348/000709904X22278

Guptal, G., \& Kumar, A. (2016). Role of Packaging in Influencing Consumers' Buying Behavior. International Journal of Research in Management, Science \& Technology, 4(3), 53-63.

Hsee, C. K. (1996). The evaluability hypothesis: An explanation for preference reversals between joint and separate evaluations of alternatives. Organizational behavior and human decision processes, 67(3), 247-257. https://doi.org/10.1006/obhd.1996.0077

Kahneman, D. (2003). A perspective on judgment and choice: mapping bounded rationality. American Psychologist, 58(9), 697. https://doi.org/10.1037/0003-066X.58.9.697

Kahneman, D. (2011). Thinking, fast and slow. Published by arrangement with Farrars, Traus, and Giroux.

Krider, R. E., Raghubir, P., \& Krishna, A. (2001). Pizzas: $\pi$ or square? psychophysical biases in area comparisons. Marketing Science, 20(4), 405-425. https://doi.org/10.1287/mksc.20.4.405.9756

Kuhn, D. (2001) How do people know? Psychological Science, 12, 1-8. https://doi.org/10.1111/1467-9280.00302

Kuvykaite, R., Dovaliene, A., \& Navickiene, L. (2009). Impact of package elements on consumer's purchase decision. Economics and Management, (14), 441-447.

LeBoeuf, R. A., \& Norton, M. I. (2012). Consequence-cause matching: Looking to the Consequences of events to infer their causes. Journal of Consumer Research, 39. https://doi.org/10.1086/662372

Lombrozo, T. (2006). The structure and function of explanations. Trends in Cognitive Sciences, 10(10), 464-470. https://doi.org/10.1016/j.tics.2006.08.004

Raghubir, P., \& Greenleaf, E. A. (2006). Ratios in proportion: what should the shape of the package be? Journal of Marketing, 70(2), 95-107. https://doi.org/10.1509/jmkg.70.2.095

Rozin, P., \& Nemeroff, C. (2002). Sympathetic Magical Thinking: The Contagion and Similarity “Heuristics.” In Gilovich, T., Griffin, D., \& Kahneman, D. (Eds.), Heuristics and biases: The psychology of intuitive judgment. Cambridge: Cambridge University Press. https://doi.org/10.1017/CBO9780511808098.013

Rozin, P., Markwith, M., \& Ross, B. (1990). The sympathetic magical law of similarity, nominal realism and neglect of negatives in response to negative labels. Psychological Science, 1(6), 383-384. https://doi.org/10.1111/j.1467-9280.1990.tb00246.x

Rozin, P., Millman, L., \& Nemeroff, C. (1986). Operation of the laws of sympathetic magic in disgust and other domains. Journal of Personality and Social Psychology, 50(4), 703. https://doi.org/10.1037/0022-3514.50.4.703

Saporta-Sorozon, K., \& Bar-Eli, M. (2018). The effect of previous causal knowledge on the persuasive strength of confirming covariation data. Journal of Consumer Behavior, 17(1), e90-e100. https://doi.org/10.1002/cb.1688 
Saporta-Sorozon, K., (2018). "God is in the Details": The effect of directional verbs in process explanations on text coherence. Global Journal of Management and Business Research: E Marketing, 18(1), 1-13.

Saporta-Sorozon, K., Danziger, S., \& Sloman, S. (2017). Causal models drive preference between drugs that treat a focal versus multiple symptoms. Journal of Behavioral Decision Making, 30(4), 794-806. https://doi.org/10.1002/bdm.1999

Spence, C., \& Ngo, M. K. (2012). Assessing the shape symbolism of the taste, flavour, and texture of foods and beverages. Flavour, 1(1), 12. https://doi.org/10.1186/2044-7248-1-12

Stanovich, K. E., \& West, R. F. (2000). Individual differences in reasoning: Implications for the rationality debate? Behavioral and Brain Sciences, 23(5), 645-665. https://doi.org/10.1017/S0140525X00003435

Tversky, A., \& Kahneman, D. (1983). Extensional versus intuitive reasoning: The conjunction fallacy in probability judgment. Psychological Review, 90(4), 293-315. https://doi.org/10.1037/0033-295X.90.4.293

Van Prooijen, J. W., \& van Dijk, E. (2014). When consequence size predicts belief in conspiracy theories: The moderating role of perspective taking. Journal of Experimental Social Psychology, 55, 63-73. https://doi.org/10.1016/j.jesp.2014.06.006

White, P. A. (2005). The power PC theory and causal powers: Comment on Cheng (1997) and Novick and Cheng (2004). Psychological Review, 112, 675-684. https://doi.org/10.1037/0033-295X.112.3.675

Yang, S., \& Raghubir, P. (2005). Can bottles speak volumes? The effect of package shape on how much to buy. Journal of Retailing, 81(4), 269-281. https://doi.org/10.1016/j.jretai.2004.11.003

\section{Copyrights}

Copyright for this article is retained by the author(s), with first publication rights granted to the journal.

This is an open-access article distributed under the terms and conditions of the Creative Commons Attribution license which permits unrestricted use, distribution, and reproduction in any medium, provided the original work is properly cited. 